
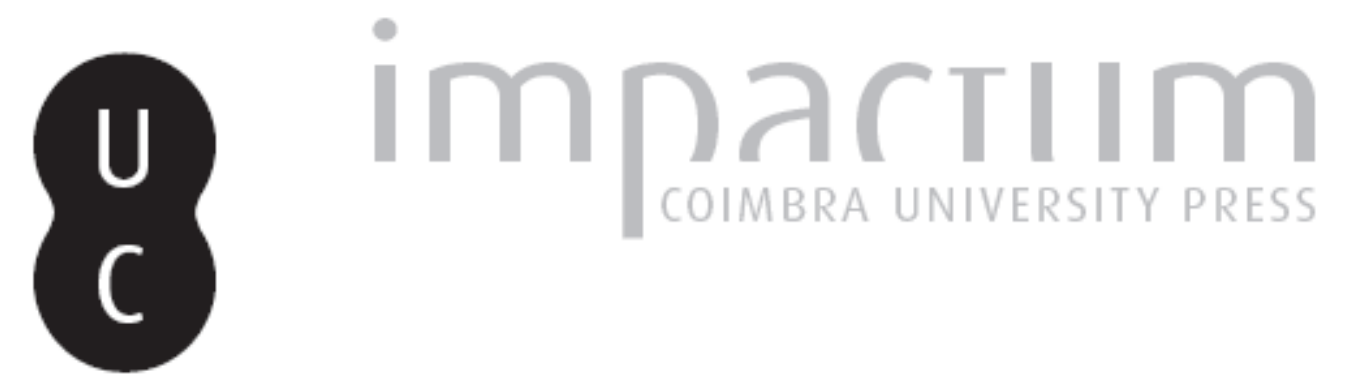

\title{
Condições de habitabilidade ou naturae decor no Antigo Egipto segundo um «canto de carpideiras»
}

\author{
Autor(es): $\quad$ Pereira, J. M. Simões
}

Publicado por: Centro de História da Universidade de Lisboa

URL persistente:

URI:http://hdl.handle.net/10316.2/23789

DOI:

DOI:http://dx.doi.org/10.14195/0871-9527_19_12

Accessed : $\quad$ 26-Apr-2023 00:49:08

A navegação consulta e descarregamento dos títulos inseridos nas Bibliotecas Digitais UC Digitalis, UC Pombalina e UC Impactum, pressupõem a aceitação plena e sem reservas dos Termos e Condições de Uso destas Bibliotecas Digitais, disponíveis em https://digitalis.uc.pt/pt-pt/termos.

Conforme exposto nos referidos Termos e Condições de Uso, o descarregamento de títulos de acesso restrito requer uma licença válida de autorização devendo o utilizador aceder ao(s) documento(s) a partir de um endereço de IP da instituição detentora da supramencionada licença.

Ao utilizador é apenas permitido o descarregamento para uso pessoal, pelo que o emprego do(s) título(s) descarregado(s) para outro fim, designadamente comercial, carece de autorização do respetivo autor ou editor da obra.

Na medida em que todas as obras da UC Digitalis se encontram protegidas pelo Código do Direito de Autor e Direitos Conexos e demais legislação aplicável, toda a cópia, parcial ou total, deste documento, nos casos em que é legalmente admitida, deverá conter ou fazer-se acompanhar por este aviso.

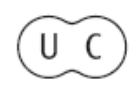



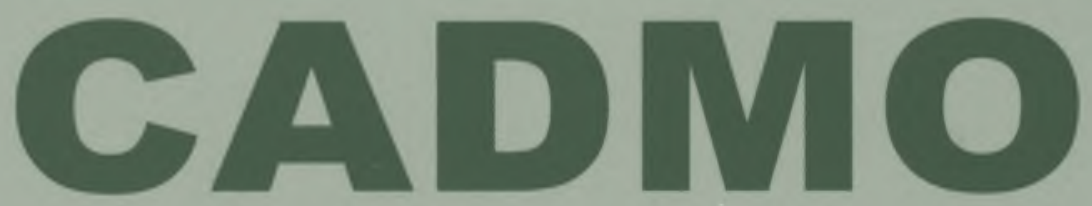

Revista de História Antiga

\author{
Centro de História \\ da Universidade de Lisboa
}

19

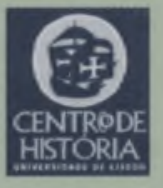

430 =

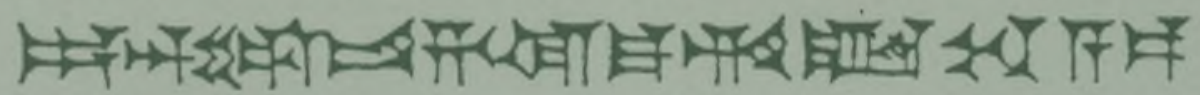

MHNIN AEI $\Delta$ E $\Theta E A ~ \Pi H \Lambda H I A \triangle E \Omega$ 


\title{
CONDIÇÕES DE HABITABILIDADE OU NATURAE DECOR NO ANTIGO EGIPTO SEGUNDO UM «CANTO DE CARPIDEIRAS" DO IMPÉRIO MÉDIO
}

\author{
J. M. SIMÕES PEREIRA \\ Bolseiro de pós-doutoramento da FCT \\ jm.simoes.ferreira@sapo.pt
}

Num "canto de carpideiras", tal como ele aparece relatado numa das muitas inscrições de uma tumba ${ }^{(1)}$ do tempo do faraó Ramsés II (1289-1224 a. C.), e no contexto de uma descrição realista da terra dos mortos, "O Ocidente" (Amentet), e das duras condições de existência a que estavam sujeitos os que a essa inóspita e desértica região baixavam, e nela tinham de permanecer, privados da verdadeira vida, condenados a um sombrio, forçado e eterno repouso(2), pode-se, por interpretação analógica e considerando o contrário ou as antinomias, deduzir o que os antigos Egípcios pensariam daquilo que hoje se chamaria "as condições de habitabilidade" de uma casa, o que na teoria da arquitectura vitruviana seria formulado como fazendo parte do naturae decor ${ }^{(3)}$. - Veja-se:

As carpideiras dizem:

«A casa dos que estão no Ocidente,

é profunda e escura.

Não tem porta, nem janelas,

nem luz para iluminar,

nem o vento do Norte para refrescar o coração.

O sol não entra nessa casa.

Eles dormem durante todo o tempo

Porque as trevas se estendem pelo dia.

Meu deus! Como o bom [o morto] estaria bem [vivo?]

se 0 ar fosse respirável.»(4) 
Estando, deste modo, contemplados os aspectos negativos ou carências impossibilitadoras da sobrevivência, pode-se, considerando os contrários, deduzir as condições de habitabilidade tidas como positivas, propícias à vida. - E estas seriam:

1) uma casa deveria ser larga e clara, ou, pelo menos, não muito "profunda" nem "escura";

2) deveria ter porta para acesso, e janelas por onde entrasse a "luz para iluminar";

3) idem, para ventilar, ou para «o vento do Norte ${ }^{(5)} \ldots$ refrescar o coração"(6);

4) idem, que, em geral, "o ar fosse respirável», o que possibilitaria "estar bem", viver.

Pouco sobrou das casas de habitação dos antigos Egípcios. Sabe-se que eram de barro, em taipa ou tijolo cozido ao sol, com estrutura dos pavimentos elevados, tectos e coberturas em madeira e junco; mas das suas fundações e do traçado das casas, aí representado, tal como as escavações arqueológicas o tem revelado, pode-se deduzir, pelas condições negativas ou proscrições aqui assinaladas e considerando os contrários, que as correspondentes prescrições ou condições de habitabilidade positivas se faziam observar.

Com efeito, mesmo nas modestas casas dos trabalhadores na construção das pirâmides e templos funerários se apresentam traçados, dimensões e proporções que contemplam o essencial daquilo que se pode considerar boas condições para habitar: compartimentos com áreas adequadas, em forma de rectângulos regulares, bem proporcionados e bem articulados, quase sempre dispostos para um pátio interior, que seria o núcleo gerador da composição e disposição da habitação, por assim dizer, o coração da casa, onde a maior parte das actividades domésticas do quotidiano, como cozinhar, lavar, coser, tecer, etc., se processariam; havia uma porta para o exterior; janelas, postigos e frestas para iluminação solar e lunar (que é considerável em países de céu límpido) e para ventilação; escada para acesso à cobertura que, dada a secura do clima, era plana, em terraço, permitindo cómoda utilização.

Depois, é ainda de considerar a existência de pequenas caves para arrecadação e conservação de géneros alimentícios, e a existência de dispositivos destinados ao culto religioso, como altares, nichos para os deuses lares, e adossada a uma das pa-redes limítrofes, a porta falsa, ou seja, a imagem ou representação de uma porta por 
onde os kau dos mortos familiares entrariam e sairiam ${ }^{(7)}$. Mas noutro tipo de casas, bem menos modestas, destinadas às classes ou estados superiores chegava-se ao requinte de haver pátios porticados, com colunas de pedra e, envolvidos por altos muros e pórticos de colunas, por vezes com entradas monumentais, jardins interiores com espelhos de água, fontes, árvores sombreadoras e de fruto, e flores de várias espécies, com toda a sua gama de cores e odores diversos ${ }^{(8)}$.

Ainda, uma coisa notável é de salientar: em todas as casas, mesmo nas mais modestas, havia instalações sanitárias e para banho, o que demonstra a grande atenção dada aos factores de higiene para a obtenção de boas condições de habitabilidade, o mesmo é dizer, que boas condições de vida, o que se denota, sinteticamente, naquela expressão do canto das carpideiras de que até o morto "estaria bem" caso "o ar fosse respirável». De resto, a procura de condições climáticas, ou ambientais, justas e adequadas seria o aspecto mais saliente de toda a construção habitacional em barro, como se constata pelo estudo das ruínas de Amarna-Akhetaton ${ }^{(9)}$, mas que também se pode observar noutras ruínas urbanas, e de que há reflexos em vários tipos de testemunhos e documentos, como o "Lamento da Viúva" ou "Canto das Carpideiras", que foi escolhido como exemplo.

Ora, a questão climática, ou a qualidade dos ares, considerada globalmente como exposição aos quadrantes solares e aos ventos dominantes, a par da qualidade das águas, é a preocupação primeira e maior de Vitrúvio (c. $90-20$ a. C.) ${ }^{(10)}$ para a prossecução dos loci saluberrimi onde localizar a cidade (Liv. I, C. IV, 1) ${ }^{(11)}$, no que se terá inspirado em Hipócrates (460-366 a. C. $)^{(12)}$ ou nos Tratados Hipocrá$t_{i} \cos ^{(13)}$. Mas também, no relativo às casas, as condições de habitabilidade, vistas como fazendo parte daquilo a que formula como "decoro natural» (naturae decor), são objecto de várias observações de Vitrúvio, designadamente no Liv. I, C. II, 7, prescrevendo a eleição de regiões saudáveis, e a orientação solar mais conveniente dos edifícios e dos diversos compartimentos de habitação(14), ou mais extensamente, ocupando todo o Liv. VI, em especial o C. I, 1-12 e C. IV, 1-2 $2^{(15)}$. - Assim, mais uma vez, em documentos da antiga cultura egípcia, aparecem registadas noções que, mais tarde, viriam a ser formuladas, teoricamente, de um modo explícito, com fundamentação e desenvolvimento, como categorias e conceitos determinantes, na teoria da arquitectura.

A higiene ou santé, como aparece designada por Pierre Le Muet $(1591-1669)^{(16)}$, no seu tratado Manière de bien bastir pour toutes sortes de personnes ${ }^{(17)}$, de 1623 , com várias reedições e traduções ao 
longo do século XVII, chegaria a ser colocada, a par das vitruvianas firmitas, utilitas e venustas - ou durée, aisance ou commodité, e la belle ordonnance, segundo os termos congéneres usados por este tratadista ${ }^{(18)}$-, como categoria finalística da arquitectura, ainda que considerando que la santé des appartments, fazia parte da categoria mais geral da aisance ou commodité, ou seja, da vitruviana utilitas ${ }^{(19)}$, que se deveria observar em todas as edificações. De resto, a partir do século XVIII, o factor higiénico, a sanidade, designadamente do(s) $\operatorname{ar}(e s)$, seria o mais saliente na argumentação teórica e ideológica(20) - por vezes até com laivos de panaceia - dos que se propunham reordenar os países, as cidades, e as sociedades do Ocidente, chegando aos nossos dias.

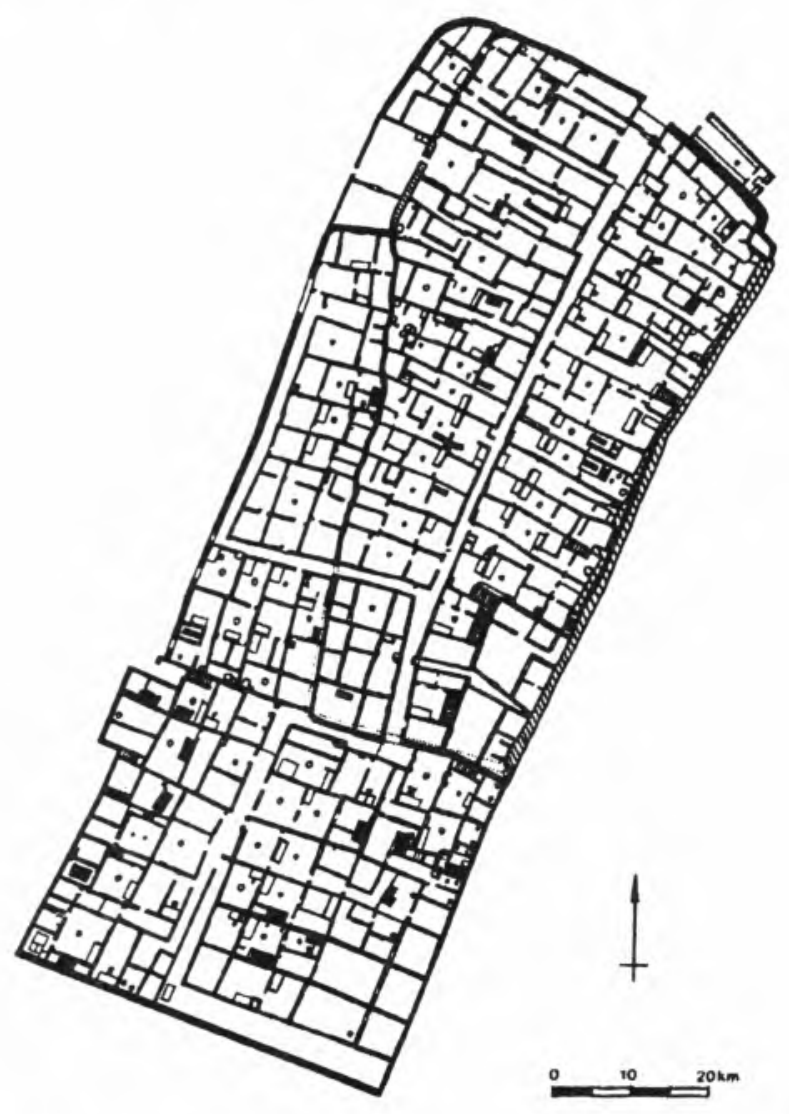

1. Deir El-Medina. Planta da cidade dos construtores do templo funerário de Hatchepsut (c. 1480-1458), in Uphill, E. P., Egyptian Towns and Cities, Buckinghamshire, 1988, p. 22 , ill. 8 . 

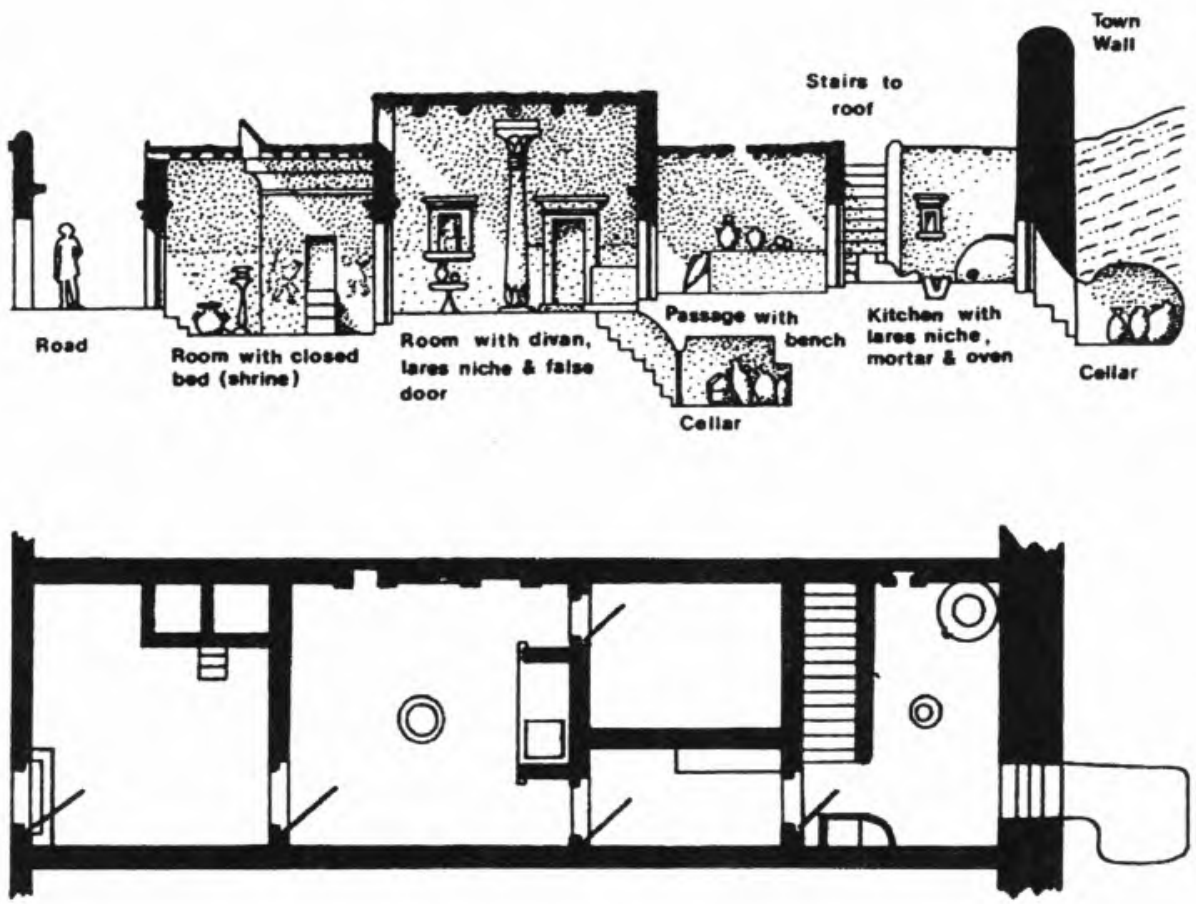

2. Deir El-Medina. Reconstrução de uma casa típica em planta e corte, in Uphill, ob. cit. (1988), p. 24, ill. 10. 

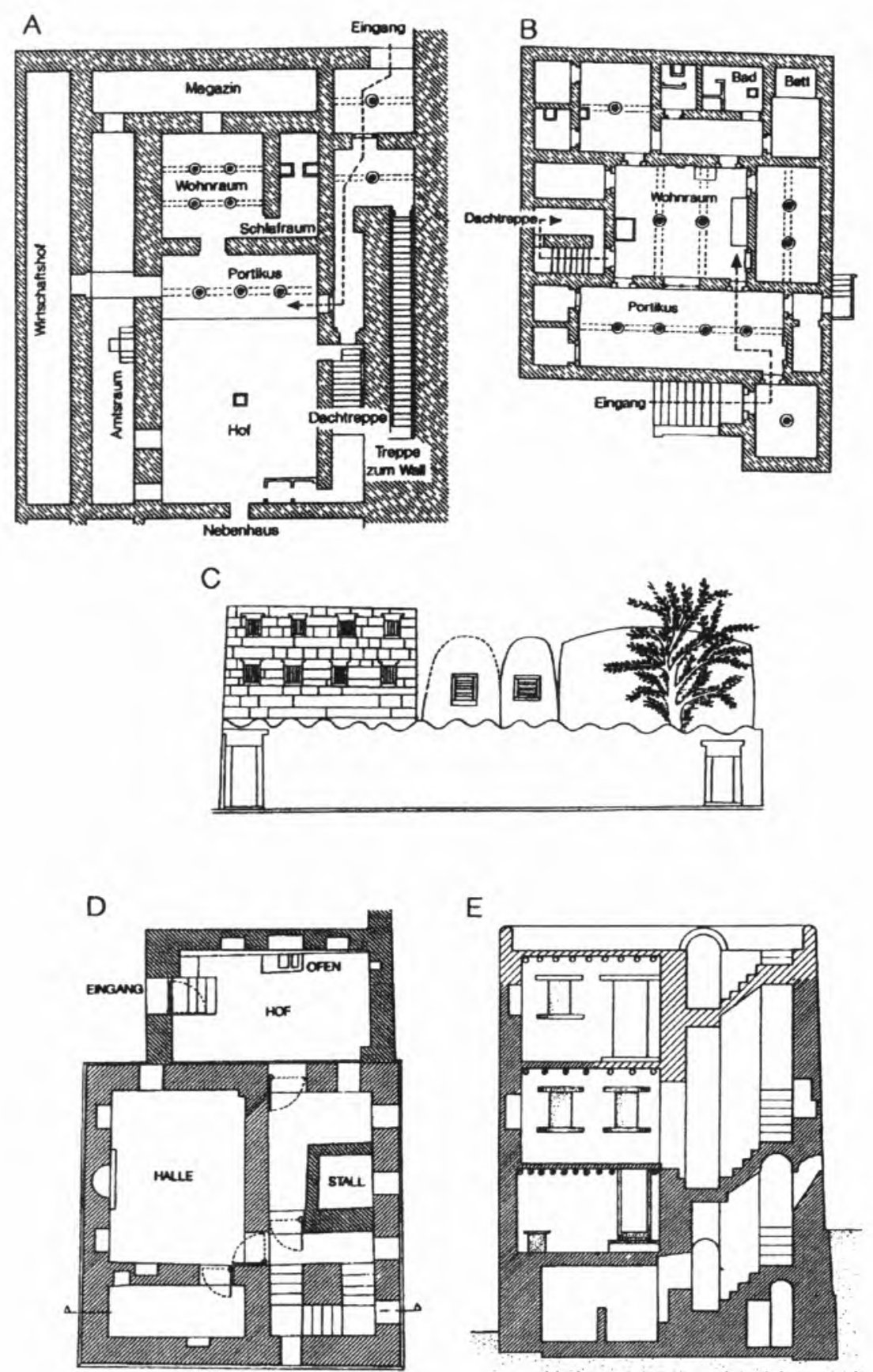

3. Kahun. Planta da casa de um alto funcionário e exemplos de casas de trabalhadores, in Uphill, ob. cit. (1988) - Desenhos de H. Jaeschke, em todos os casos. 


\section{Notas}

(1) OSING, J., Das Grab des Nefersecheru in Zawiyet Sultan, Mainz, 1992, 54 f. Nefersecheru terá sido um cortesão, escriba e funcionário do tempo de Ramsés II, cuja tumba foi explorada por J. Osing.

(2) A par das várias representações que expressam confiança de uma sobrevivência gloriosa no Além, após a morte, numa espécie de Eliseu, na cultura egípcia há também representações que exprimem o contrário: o aniquilamento, sem tipo algum de sobrevivência, ou, quanto muito, uma existência como fantasma num lugar subterrâneo e sombrio, que parece prefigurar o Hades dos gregos ou o Sheol dos hebreus. É a este tipo de representações que, na esteira de Jan Assmann, se designa de realistas. - Ver ASSMANN, J., Tod und Jenseits im alten Ägypten, München, 2001, p. 197: "Die ägyptische Todeswelt unterscheidet sich grundsätzlich nicht vom Land ohne Wiederkehr, von der Sche'ol und dem Hades. Die Gegenbilder eines Elysiums haben das Schreckensbild der Sche'ol in keiner Weise verdeckt". Para mais, também no "Livro dos Mortos", no capítulo 175, se apresenta uma visão da terra dos mortos como «um deserto, que não tem água, que não tem ar, que é muito profundo e escuro, e completamente ilimitado", in LOPES, M. H., O Livro dos Mortos do Antigo Egipto, Lisboa, 1991, pp. 268-269; idem, BARGUET, P., Le Livre des Morts des anciens égyptiens, Paris, 1967, p. 261.

(3) Vitruve, De l'architecture (De architectura), Livre I, II, 7, texte établi, trad. et commenté par Ph. Fleury, Paris, 1990, p. 18: "Naturalis autem decor sic erit si primum omnibus templis saluberrimae regiones aquarumque fontes in his locis idonei eligentur in quibus fana constituantur (...) Item naturae decor erit si cubiculus et bibliothecis ab oriente lumina capiuntur, balneis e hibernaculis ab occidente hiberno, pinacothecis et quibus certis luminibus opus est partibus, a septrentione quod ea caeli regio neque exclaratur neque obscuratur solis cursu, sed est certa inmutabilis die perpetuo."

(4) Lamento da Viúva ou Canto das Carpideiras, inscrito na tumba de Nefersecheru; ver, OSING, ob. cit. (1992), 54 f., in Assmann, ob. cit. (2001), p. 188.

(5) Por "vento do Norte" deve-se entender a fresca brisa marítima, soprando do Mediterrâneo, naturalmente menos quente do que o ar dos tórridos desertos que cercavam o Nilo, cujas margens eram a zona habitada do Egipto.

(6) É de lembrar que o coração, para os antigos Egípcios, era o centro da sensibilidade e do pensamento, além de o ser, também, dos sentimentos, dos desejos e da vontade. Assim, o órgão ou Superorgans determinante da vida individual e social. - Veja-se BRUNNER, H., "Herz", in Helck, W. e Westendorf, W. (eds.), Lexikon der Ägyptologie, II, Wiesbaden, 1977, cols. 1158-1168; ver ainda, SOUSA, R., "Coração", in Luís Manuel de Araújo (dir.), Dicionário do Antigo Egipto, Lisboa, 2001, pp. 234-236.

(7) Ver BRINKS, J., "Haus", in Helck, W. e Westendorf, W. (eds.), Lexikon der Ägyptologie, II, Wiesbaden, 1977, cols. 1055-1061; idem, ARNOLD, D., "Hausbau", in Helck, W. e Westendorf, W. (eds.), Lexikon der Ägyptologie II, cols. 1062-1064; BORCHARDT, L. e RICKE, H., Die Wohnhäuser in Tell el-Amarna, Berlin, 1980, 2 Be; UPHILL, E. P., Egyptian Towns and Cities, Buckinghamshire, 1988; ARNOLD, F., "A Study of Egyptian Domestic Building", in Varia Aegyptiaca 5, 1989, pp. 75-93; VALBELLE, D., La vie dans l'Egypte ancienne, Paris, 1992; MACHADO, M. J., "Casa", in Luís Manuel de Araújo (dir.), Dicionário do Antigo Egipto, Lisboa, 2001, pp. 187-188.

(8) DZIONARA, K., "Der Garten im Alten Ägypten", in Sarkowicz, H. (ed.), Die Geschichte der Gärten und Parks, Frankfurt am Main, 2001; idem, WILKINSON, A., The Garden in 
Ancient Egypt, London, 1998; GOTHEIN, M.-L., Geschichte der Gartenkunst, I. Bd: Von Ägypten bis zur Renaissance in Italien, Spanien und Portugal (1914, 2. Aufl. 1926), Nachdruck, Hildesheim, 1977; BONNECHERE, P. et DE BRUYN, O., L'art et l'âme des jardins, de l'Egypte pharaonique à l'époque contemporaine, une histoire culturelle de la nature dessinée par l'homme, Paris, 1998, Mercator.

(9) ENDRUWEIT, A., Städtischer Wohnbau in Ägypten: Klimagerechte Lehmarchitektur in Amarna, Berlin, 1994. O autor intenta mostrar que a construção urbana habitacional procurava, acima de tudo, propociar condições climáticas justas (gerechte), sendo a arquitectura das casas determinada por tal.

(10) Sobre Vitrúvio, ver: JOLLES, J. A., Vitruvius Ästhetik, Friburgo, 1906; SONTHEIMER, L., Vitruv und seine Zeit, Tubinga, 1908; CHOISY, A., Vitruve, Paris, 1910; BIRNBAUM, A., Vitruvius und die griechische Architektur, Viena, 1914; WISTRAND, E., Vitrustudier, Gotenburg, 1933; PELLATI, F., Vitruvio, Roma, 1938; STUERZENACKER, E., Vitruvius über die Baukunst, Essen, 1938; RUFFEL, P. et SOUBIRAN, J., "Recherches sur la tradition manuscrite de Vitruve", in Pallas IX, Fascicule 3, (Extrait), Toulouse, 1959; MARTIN, R., "Vitruvius", in Enciclopedia Universal dell'Arte, XIV, 1966, p. 832-837; KNELL, H. e BURKHARDT, H. (eds.), Vitruv-Kolloqium des Deutschen Archäologen-Verbades, Darmstad, 1984; KNELL, H., Vitruvs Architekturtheorie. Versuch einer Interpretation, Darmstad, 1985; CALLEBAT, C., FLEURY, Ph. et altri, Dictionnaire des termes techniques du "De Architectura" de Vitruve, Hildesheim, 1995, Georg Olms Verlag; GROS, P., Vitruve et la tradition des traitès d'architecture: Fabrica e Ratiocinatio. Recueil d'Ėtudes, Rome, 2006. - Especificamente, para a questão do naturae decor, ou factores da salubridade, em Vitrúvio, ver: SÖLLNER, A., Die hygienische Anschauugen des römischen Architekten Vitruvius, Jena, 1913, G. Fischer.

(11) Vitruve, De l'architecture (De architectura), Livre I, IV, 1, texte établi, traduit et commenté par Ph. Fleury, Paris, 1990, $2^{\circ}$ tirage 2003, CUF / Les Belles Lettres, p. 20ss..

(12) Sobre Hipócrates, ver: EDELSTEIN, L., Peri Aeron und die Sammlung der hippokratischen Schriften, Berlin, 1931; WEIDMANN; id., Ancient Medicine: Selected Papers of..., ed. by O. Temkin and C. L. Temkin, transl. from the German by C. L. Temkin, Baltimore, 1967, new ed. 1987, John Hopkins Univ. Press; JOUANNA, J., Hippocrate. Pour une archéologie de l'école de Cnide, Paris, 1974, Les Belles Lettres; SMITH, W. D., Hippocratic Tradition, Ithaca, NY, 1979, Cornell Univ. Press; JOUANNA, J., Hippocrate, Paris, 1992, Fayard; PINAULT, J. R., Hippocratic Lives and Legends, Leiden / New York / Köln, 1992, Brill Academic Publishers; JOUANNA, J., "Hippocrate et la Collection hippocratique dans l'Ars medicinae", in Revue d'Histoire des Textes XXIII, 1993, pp. 123-158; VITRAC, B., Médecine et philosophie au temps d'Hippocrate, Paris, 1995, PUV; JORI, A., Medicina e medici nell'antica Grecia. Saggio sul "Peri téchnes" ippocratico, Bologna, 1996, Ed. il Molino; OLIVEIRA MARQUES, A. H. (ed.), Hipócrates e a Arte da Medicina, Lisboa, 1999, Ed. Colibri; SIMÕES FERREIRA, J. M., "Hipócrates e os "Tratados Hipocráticos": ou o primado da Salubridade e do Ambiente, na escolha de Lugar para a Cidade", 2009, artigo a publicar e a integrar no estudo, A Teoria da Arquitectura nos Mitos e Ideias Primordiais da Antiguidade: Da Antiga Mesopotâmia e Antigo Egipto à Grécia e Roma, de Vitrúvio, investigação a decorrer apoiada por uma BPD, da FCT / MCTES.

(13) Hipócrates, "Sobre los aires, águas y lugares", in Tratados Hipocráticos II, trad., introd. y notas por J. A. López Férez, Madrid, 1997, pp. 39-88; também, Hippocrate, Airs, eaux, lieux, texte établi et trad. par J. Jouanna, Paris, 1996, deux. tirage 2003, CUF / Les Belles Lettres.

(14) Vitruve, ob. cit., Livre I, II, 7 (1990), p. 18. 
(15) Vitruve, De l'architecture (De architectura), Livre VI, I, 1-12, IV, 1-2, texte établi, traduit et commenté par L. Callebat, Paris, 2004, CUF / Les Belles Lettres, p. 5-11, e pp. 19-20. - Nestas passagens há referências ao Egipto: “Haec autem ita erunt recte disposita, si primo animaduersum fuerit quibus regionibus aut quibus inclinationibus mundi constituantur. Namque aliter Aegypto, aliter Hispania, non eodem modo Ponto, dissimiliter Romae, item ceteris terrarum et regionum proprietatibus oportere uidentur constitui genera aedificiorum quod alia parte solis cursu premitur tellus, alia longe ab eo distat, alia per medium temperatur." - Trad. em francês: "Or la première condition d'une construction bien adaptée est de tenir compte de la région d'implantation et de sa latitude. Car l'architecture des bâtiments doit être manifestement conçue suivant un type particulier en Égypte, particulier en Espagne, autre dans le Pont, différent à Rome, et ainsi, dans tous les cas, en fonction des caractères propes aux terres et aux régions: si dans telle partie du monde, en effet, la trajectoire du soleil rase la terre, elle en est fort distante dans telle autre et, dans une autre, se situe en position moyenne et tempèré" (C. I, 1, p. 5). Referências também à importância do Sol: "ılta uidetur mundi conceptio tota propter inclinationem consonantissime per solis temperaturam ad harmoniam esse composita." - Trad. em francês: "Du fait de son inclinaison et en fonction de la température que donne le soleil, le système du monde paraît ainsi composer, dans un accord parfait, un tout harmonieux" (C. I, 6, p. 8). - Nestas passagens, dado o seu significado, optou-se pelas duas versões.

(16) Sobre Pierre Le Muet, ver: GRASSI, G., La costruzione logica dell'architettura, Padova, 1967, Marsilio Editori; BLUNT, A., "Introduction", in Le Muet, P., Manière de bien bastir pour toutes sortes de personnes, reprint ed. Paris 1647, with the addition of a new introd. by..., Richmond, 1972, Greg Press; MIGNOT, C., Pierre Le Muet, architecte (1591-1669), Thèse de doctorat, Paris-Soborne, 1991 (éd. microfichée, Lille III); SIMÕES FERREIRA, J. M., Arquitectura, Desenho Urbano e Tratadistica: De Aldo Rossi a Vitrúvio ou o "Breviário Mediterrânico" da Teoria da Arquitectura e do Desenho Urbano, dissertação de mestrado em Desenho Urbano, Lisboa, 1999, ISCTE, 4 vols. As referências a Pierre Le Muet encontram-se no Cap. 11, II. ${ }^{a}$ Parte, II. ${ }^{\circ}$ Volume. - Há exemplares na BNL.

(17) LE MUET, P., Manière de bien bastir pour toutes sortes de personnes, Paris, 1623. - Desta edição existe um exemplar em bom estado na BNL. - Todavia, hoje, as que são tidas como edições de referência para fins de estudo, é a $2 .^{a}$ ed. de 1647 , acrescida de "Augmentations de nouveaux bastiments faits en France par les ordes \& desseins du Sieur Le Muet", de que há da reed. facsimil de Anthony Blunt, Richmond, 1972, Greg Press; e a $3 .^{\text {a }}$ ed. de 1664 , reed. por C. Mignot, Clamecy, 1981, Pandora. Ambas as ediçōes contêm estudos introdutórios e notas. - A edição de 1647 e uma "Notice bibliographique" de C. Mignot, de 2005, são consultáveis através do site www.architectura.cesr.univ-tours.fr/.

(18) LE MUET, ob. cit., Sommaire discours (1623), p. 1.

(19) Esta é a interpretação de KRUFT, H.-W., Geschichte der Architekturtheorie: von der Antike bis zur Gegenwart, München, 1985, Studienausgabe 4. Auflage 1995, C. H. Beck, p. 139.

(20) Ver, SIMÕES FERREIRA, J. M., Arquitectura para a Morte: A Questão Cemiterial e seus reflexos na Teoria da Arquitectura, Lisboa, 2005, FCSH/UNL, 3 vols., dissertação de doutoramento em História e Teoria das Ideias. - Aprovada, em concurso público, promovido pela FCT/MCTES e Fundação Gulbenkian, em 2007, para publicação pela Fundação Gulbenkian na colecção "Textos de Ciências Sociais e Humanas". 


\section{Bibliografia (citada ou referida no texto)}

ARNAU AMO, J., La Teoría de la Arquitectura en los Tratados. I. Vitruvio, Madrid: Tebas Flores, 1988

ARNOLD, D., «Hausbau», in Wolfgang Helck e Wolfhart Westendorf (eds.), Lexikon der Ägyptologie II, Wiesbaden: Otto Harrassowitz, 1977, cols. 1062-1064

ARNOLD, F., "A Study of Egyptian Domestic Building", in Varia Aegyptiaca 5, 1989, pp. 75-93

ASSMANN, J., Tod und Jenseits im Alten Ägypten, Munique: C. H. Beck., 2001

BARGUET, P., Le Livre des Morts des anciens égyptiens, trad., introd. et commentaire de..., Paris: Éditions du Cerf., 1967

BIRNBAUM, A., Vitruvius und die griechische Architektur, Viena: Hölder, 1914

BLUNT, A., "Introduction», in LE MUET, P., Manière de bien bastir pour toutes sortes de personnes, reprint ed. Paris, 1647, with the addition of a new introd. by..., Richmond: Greg Press, 1972

BONNECHERE, P. e DE BRUYN, O., L'art et l'âme des jardins, de l'Egypte pharaonique à l'époque contemporaine, une histoire culturelle de la nature dessinée par l'homme, s./l.: Mercator, 1998

BORCHARDT, L. e RICKE, H., Die Wohnhäuser in Tell el-Amarna (Ausgrabungen der Deustchen Orient-Gesellschaft in Tell El-Amarna, Bd. 5), Berlim: Gebr. Mann, 2 Be., 1980

BRINKS, J., "Haus", in Wolfgang Helck e Wolfhart Westendorf (eds.), Lexikon der Ägyptologie II, Wiesbaden: Otto Harrassowitz, 1977, cols. 1055-1061

BRUNNER, H., "Herz", in Wolfgang Helck e Wolfhart Westendorf (eds.), Lexikon der Ägyptologie II, Wiesbaden: Otto Harrassowitz, 1977, cols. 1158-1168

CAllebAT, C., FleURY, Ph. et al., Dictionnaire des termes techniques du "De Architectura" de Vitruve, Hildesheim: Georg Olms Verlag, 1995

CHOISY, A., Vitruve, Paris: Lahure, 1909

DZIONARA, K., "Der Garten im Alten Ägypten", in Sarkowicz, H. (ed.), Die Geschichte der Gärten und Parks, Frankfurt am Main: Insel, 2001

EDELSTEIN, L., Peri Aeron und die Sammlung der hippokratischen Schriften, Berlim: Weidmann.1931

- Ancient Medicine: Selected Papers of..., ed. by O. Temkin and C. L. Temkin, transl. from the German by C. L. Temkin, Baltimore: John Hopkins Univ. Press, 1967 (new ed. 1987)

ENDRUWEIT, A., Städtischer Wohnbau in Ägypten: Klimagerechte Lehmarchitektur in Amarna, Berlim: Gebr. Mann Verlag, 1994

SOUSA, Rogério, "Coração", in Luís Manuel de Araújo (dir.), Dicionário do Antigo Egipto, Lisboa: Editorial Caminho, 2001, pp. 234-236.

GOTHEIN, M.-L., Geschichte der Gartenkunst, I. Bd: Von Ägypten bis zur Renaissance in Italien, Spanien und Portugal (1914, 2. Aufl. 1926), Nachdruck, Hildesheim: G. Olms, 1977

GRASSI, G., La costruzione logica dell'architettura, Pádua: Marsilio Editori, 1967 
GROS, P., Vitruve et la tradition des traitès d'architecture: Fabrica e Ratiocinatio. Recueil d'Ėtudes, Rome: École Française de Rome, 2006

HIPÓCRATES, "Sobre los aires, águas y lugares", in Tratados Hipocráticos II, trad., introd. y notas por J. A. López Férez, Madrid: Gredos, 1997, pp. 39-88.

JOLLES, J. A., Vitruvius Ästhetik, Friburgo: C. A. Wagner, 1906

JORI, A., Medicina e medici nell'antica Grecia. Saggio sul "Perì téchnes" ippocratico, Bolonha: Molino, 1996

JOUANNA, J., Hippocrate. Pour une archéologie de l'école de Cnide, Paris, 1974, Les Belles Lettres

- Hippocrate, Paris: Ed. Fayard, 1992

- «Hippocrate et la Collection hippocratique dans l'Ars medicinae", in Revue d'Histoire des Textes, XXIII, 1993, pp. 123-158

KNELL, H. e BURKHARDT, H. (eds.), Vitruv-Kolloqium des Deutschen ArchäologenVerbades, Darmstadt: Technische Hochschule Darmstadt, 1984

KNELL, H., Vitruvs Architekturtheorie. Versuch einer Interpretation, Darmstadt: Wissenschaftliche Buchgesellschaft, 1985

KRUFT, H.-W., Geschichte der Architekturtheorie: von der Antike bis zur Gegenwart, Studienausgabe 4, Munique: C. H. Beck., 1985 (auflage 1995)

LE MUET, P., Manière de bien bastir pour toutes sortes de personnes, Paris, $1623,2^{\mathrm{e}}$ ed. $1647,3^{e}$ ed. 1664 (das duas últimas existem reedições facsimiladas descritas na nota 17)

MACHADO, Maria João, "Casa", in Luís Manuel de Araújo (dir.), Dicionário do Antigo Egipto, Lisboa: Editorial Caminho, 2001, pp. 187-188

MARTIN, R., "Vitruvius", in Enciclopedia Universal dell'Arte, XIV, 1966, pp. 832-837

MIGNOT, C., Pierre Le Muet, architecte (1591-1669), thèse de doctorat, Paris-Sorbonne, 1991 (éd. microfichée, Lille III).

- "Notice bibliographique", in Les Livres d'architecture: Le Muet, Pierre, Centre d'Études Supérieures de la Renaissance, 2005, www.architectura.cesr.univ-tours.fr/.

OliveIRA MARQUES, A. H. (ed.), Hipócrates e a Arte da Medicina, Lisboa: Ed. Colibri, 1999

OSING, J., Das Grab des Nefersecheru in Zawiyet Sultan, Mainz: Philip von Zabern, 1992

PELLATI, F., "Vitruvio nel Medioevo e nel Rinascimento", in Bollettino del Reale Istituto di Archeologia e Storia dell'Arte V, 1933, pp. 111-132

PINAULT, J. R., Hippocratic Lives and Legends, Nova lorque: Brill Academic Publishing, 1992

RUFFEL, P. et SOUBIRAN, J., "Recherches sur la tradition manuscrite de Vitruve", in Pallas IX, fasc. 3 (extrait), Toulouse, 1959

SIMÕES FERREIRA, J. M., Arquitectura para a Morte: A Questão Cemiterial e seus reflexos na Teoria da Arquitectura, dissertação de doutoramento em História e Teoria das Ideias, Faculdade de Ciências Sociais e Humanas da Universidade Nova de Lisboa, Lisboa: Fundação Gulbenkian / Fundação para a Ciência e a Tecnologia, 2009 
- Arquitectura, Desenho Urbano e Tratadística: De Aldo Rossi a Vitrúvio ou o "Breviário Mediterrânico" da Teoria da Arquitectura e do Desenho Urbano, dissertação de mestrado em Desenho Urbano, 4 vols., Lisboa: ISCTE, 1999 (há exemplares na Biblioteca Nacional)

- «Hipócrates e os Tratados Hipocráticos: ou o primado da salubridade e do ambiente, na escolha de lugar para a cidade", artigo a publicar e a integrar no estudo, A Teoria da Arquitectura nos Mitos e Ideias Primordiais da Antiguidade: Da Mesopotâmia e Antigo Egipto à Grécia e Roma, de Vitrúvio, investigação a decorrer apoiada por uma BPD, da FCT / MCTES

SMITH, W., Hippocratic Tradition, Cornell: Cornell Univiversity Press, 1979

SÖLLNER, A., Die hygienische Anschauugen des römischen Architekten Vitruvius, Jena: G. Fischer, 1913

SONTHEIMER, L., Vitruv und seine Zeit, Tubinga: J. J. Heckenhauer, 1908

STUERZENACKER, E., Vitruvius über die Baukunst, Essen: Bildgut Verlag, 1938

UPHILL, E. P., Egyptian Towns and Cities, Buckinghamshire: Shire Publ, 2001

VITRAC, B., Médecine et philosophie au temps d'Hippocrate, Paris: Presse Universitaires de France, 1995

VITRUVE, De l'architecture (De architectura). Livre I, texte établi, traduit et commenté par Ph. Fleury, Paris: CUF/Les Belles Lettres, 1990 (2 tirage 2003)

- De l'architecture (De architectura). Livre VI, texte établi, traduit et commenté par L. Callebat, Paris: CUF/Les Belles Lettres, 2004

WILKINSON, A., The Garden in Ancient Egypt, Londres: Rubicon Press, 1998

WISTRAND, E., Vitrustudier, Gotenburg: Eranos, 1933 